\title{
Conductivity Study of Tetra Aqua -1,10- Phenanthroline Zinc(II) Chloride in Aqueous Methanol Mixture at Different Temperatures
}

\author{
Firas A. Thanon \\ Department of Chemistry \\ College of Science \\ Mosul University
}

(Received 14/2/2011; Accepted 14 / 3 / 2011 )

\begin{abstract}
The electrical behavior of association phenomena of tetra aqua (1,10 - phenanthroline) zinc(II) chloride in methanol-water mixture have been investigated by precise conductance measurements at 288.15 - $308.15 \mathrm{~K}$ which can give informations about ion-ion and ionsolvent interactions in solution. The limiting molar conductance $\lambda_{\mathbf{M}}{ }^{2+}$, the association constant $\mathrm{K}_{\mathrm{A}}$ and $\mathrm{R}$ the main distance between ions in solution as a results of those interactions can be calculated. Thermodynamics parameters $(\Delta \mathrm{H}, \Delta \mathrm{G}, \Delta \mathrm{S})$ of the association processes and the coulombic forces which play an important role in the association process have been studied also.
\end{abstract}

Keywords: Tetra aqua (1,10-phenanthroline)zinc (II)chloride complex, Association constant, Conductivity measurements, Lee-Wheaton equation.

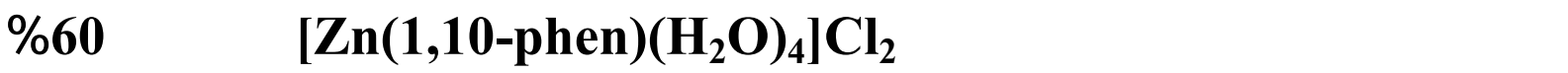 و\%0\% من الميثلنط والماءكمنيب عند مرجلت حراربة مختلة}

\section{الملغص}

تمت درلسة الخواص الكهربائية للمعدد الميثانول و الماء بوصفه منيباً بوسطة قيلست ألتوصيلية في درجلت حرارية مختلفة (288.15-308.15 K)

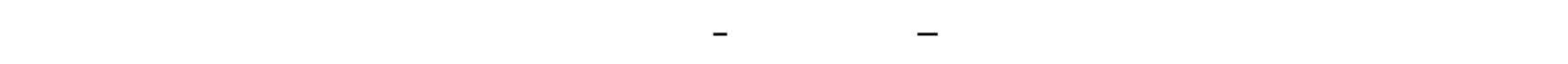

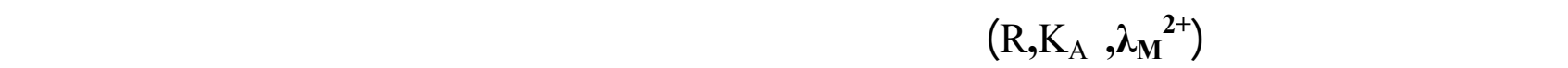

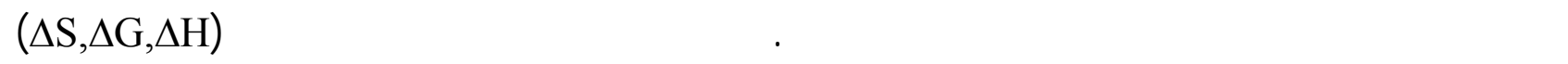
لعملية التجمع الايوني والقوى الكولومبية والتي تلعب دوراً هلما في عملية التجمع الايوني. الكاملت الدالة : المعقد (1,10-phenanthroline)zinc (II)chloride قيلسل التوصيلية، معادلة لي -ويتون. 


\section{INTRODUCTION}

Tetra aqua $(1,10$ - phenanathroline) zinc (II) chloride plays an important role in many biological processes like its effects on nucleic acid synthesis (Chang et al., 1978) and its effects on the enhances the stimulatory effect of protein kinase C activator (Kiss, 1994). The conductivity measurements are useful as an effective means to understand the nature of solute - solvent interaction since the degree of ionic mobility is exceedingly sensitive to interactions. Few works have been done on 1,10-phenanthroline and water as mixed ligand with any metal ion had studied (AL- Allaf et al., 2006 ). The analytical applications of complexes of metal ions as $\mathrm{Mn}(\mathrm{II}), \mathrm{Ni}(\mathrm{II}), \mathrm{Co}(\mathrm{II})$ and $\mathrm{Cu}(\mathrm{II})$ with 1,10 phenanthroline as ligand which have very wide applications in industry and have biological effects were studied by Lee - Wheaton equation to investigate their behavior of interaction by conductivity (Akrawi and Al-Allaf, 2002). The characteristics of metal chelate electrolytes and their solute-solvent interaction concerning charge, size and chemical properties of liquid have been elucidated by the study of the electronic spectra (Fukuda and Sone, 1972), racemization, (Meter and Newmann, 1976), optical resolution (AL- Mustawi, 2002), viscosity, molar volume (Tamingo, 1975) and conductivity (Newmann et al., 1979). The electrical conductivities of $\left[\mathrm{Fe}\left(1,10\right.\right.$-phenanthrolin) $\left.\left(\mathrm{H}_{2} \mathrm{O}\right)\right] \mathrm{Cl}_{2}$ in methanol-water mixture at different temperatures (288.15-308.15k) have been studied (Hameed et al., 2008 ).

The behavior of tetra-n-butylammonium picrate, TBAPic, in acetone - n-hexane mixed solvent, with the relative permittivity changing gradually from 20.53 to 4.99 , was studied at $25.0^{\circ} \mathrm{C}$ by using conductivity measurements. The association constants $\mathrm{K}_{\mathrm{A}}$ and the limiting molar conductivities were determined by using Lee-Wheaton equation (Palyal et al., 2010).

In this work the electrical conductivity of $\left[\mathrm{Zn}\left(1,10\right.\right.$-phenanthroline) $\left.\left(\mathrm{H}_{2} \mathrm{O}\right)_{4}\right] \mathrm{Cl}_{2}$ in methanol-water mixture at different temperatures (288.15-308.15K) have been measured to investigate the thermodynamic behaviours by application of Lee-Wheaton equation and to elucidate the conductivity parameters of assymetrical electrolytest $2: 1\left(\lambda_{0}, \mathrm{~K}_{\mathrm{A}}, \mathrm{R}\right)$ in mixed solvents.

\section{Preparation of the complex}

\section{EXPERIMENTAL}

Tetra aqua (1,10-phenanathroline) Zinc (II) chloride was prepared by mixing 2 mmole of 1,10-phenanthroline in $10 \mathrm{~cm}^{3}$ of ethanol and 2 mmole of $\mathrm{ZnCl}_{3} \cdot 4 \mathrm{H}_{2} \mathrm{O}$ in $30 \mathrm{~cm}^{3}$ of deionized water and refluxed for about $45 \mathrm{~min}$ on a water bath. On cooling and adding excess of absolute ethanol the complex was precipitated, filtered then washed with ice cold $50 \%$ ethanol and then recrystallized by slow cooling to $0{ }^{\circ} \mathrm{C}$ followed by addition of excess absolute ethanol. The product was dried under vacuum over anhydrous calcium chloride (Malik et al., 1980). The electronic spectra UV and infrared measurements were used for analysis of the complex, gas chromatography was used also to determine water content and other organic impurities.

\section{Purification of solvents}

Methanol was purified and dried by the method described by Perrin (Armargo and Perrin 1998). Conductivity water was prepared by distilling twice distilled water with specific conductance of about $2 \times 10^{-6} \mu \mathrm{s}$. Conductivity measurements were made using Jenaway PCM3 conductivity meter with frequency range of $50 \mathrm{~Hz}-1 \mathrm{kHz}$ and accuracy of 
$0.01 \mu \mathrm{s}$. The cell constant of the conductivity cell was measured using the method of Jones and Bradshaw (Jones and Bradshow, 1933). $0.01 \mathrm{M} \mathrm{KCl}$ solution was prepared from potassium chloride (BDH reagent), recrystallized three times from conductivity water and then dried at (760) torr and $500{ }^{\circ} \mathrm{C}$ for $10 \mathrm{~h}$. The cell constant was checked regularly and found to be $1.02 \mathrm{~cm}^{-1}$.

\section{Method of measurement}

A general method has been used for measuring the conductance of the measured electrolytes. The conductivity cell was washed, dried and then weighed empty and kept at any temperature $\left( \pm 0.1 \mathrm{C}^{\circ}\right)$ using a water-circulating ultra thermostat type VH5B radiometer. A certain amount solution of $\left[\mathrm{Zn}(1,10\right.$-phen $\left.)\left(\mathrm{H}_{2} \mathrm{O}\right)_{4}\right] \mathrm{Cl}_{2}$ was injected into the conductivity cell and the conductivity of the solution was measured. Successive known amount of the complex solution was added and the measurement was repeated as before. Generally (14) additions have been made for any measurement.

\section{RESULTS AND DISCUSSION}

Experimental values obtained for the equivalent conductance $\Lambda$ and the equivalent concentrations $\mathrm{C}$ for dilute solutions of $\left[\mathrm{Zn}\left(1,10\right.\right.$-phen) $\left.\left(\mathrm{H}_{2} \mathrm{O}\right)_{4}\right] \mathrm{Cl}_{2}$ in two Water (1) +Methanol (2) solvent mixtures at 288.15, 293.15,298.15,303.15 and 308.15 $\mathrm{K}$ are listed in Table 1 (A,B). Solvent correction was made to obtain the exact values of specific conductance's of the complex solutions. The experimental data were analyzed by using Lee and Wheaton equation for unsymmetrical electrolytes which is an extended form of the Debye-Hukel equation for the calculation of equivalent conductance, association constant and main distance between ions in solution (Lee and wheaton, 1978 ). For an unsymmetrical electrolyte $\mathrm{MX}_{2}$ ionizing to $\left[\mathrm{MX}^{2+}\right.$ and $\mathrm{X}^{-}$the possible association equilibrium are:

$$
\begin{aligned}
& {[M X]^{2+}+X^{-} \stackrel{K_{A}^{(1)}}{\longleftrightarrow}\{[M X] X\}^{+}} \\
& \{[M X] X\}^{+}+X^{-} \stackrel{K_{A}^{(2)}}{\longleftrightarrow}[M X] X_{2}
\end{aligned}
$$

Thus, three ionic species are present in the solution which are $[\mathrm{MX}]^{2+},\{[\mathrm{MX}] \mathrm{X}\}^{+}$and $\mathrm{X}^{-}$. All such solutions are in effect "mixed electrolyte" since the ion pair $\{[\mathrm{MX}] \mathrm{X}\}^{+}$is a conducting species.

$$
\Lambda_{\text {equiv. }}=\sum_{i=1}^{s}\left|\mathbf{z}_{i}\right| \boldsymbol{m}_{i} \lambda_{i} / \boldsymbol{C}
$$

This equation is derived as follows:

$$
\begin{aligned}
& \lambda_{i}=\boldsymbol{f}\left(\lambda_{i}^{\circ}, \varepsilon, \boldsymbol{R}\right) \\
& \sigma_{i}=C i \lambda_{i} / 1000=\left|z_{i}\right| m_{i} \lambda_{i} / 1000 \\
& \text { And } \sigma_{\text {solu }}=\sum_{i=1}^{s}\left|C_{i}\right| \\
& \text { or } \mathbf{1 0 0 0} \sigma_{\text {solu }}=\sum_{i=1}^{s}\left|C_{i} \lambda_{i}\right| \\
& \text { and } \Lambda_{\text {solu }}=\sum_{i=1}^{s}\left|z_{i}\right| m_{i} \lambda_{i} / \sum C_{i}
\end{aligned}
$$


where (s) is the number of ionic species, $\sigma$ is specific conductance, $\mathrm{C}$ stoichiometric equivalent concentration, $\lambda \mathrm{i}, \mathrm{m}_{\mathrm{i}}, \mathrm{C}_{\mathrm{i}}$ and $\mathrm{z}_{\mathrm{i}}$, are the equivalent conductance, equivalant free ion concentration, equivalent concentration and charge of the species respectively. Thus for 2:1 associated salts :

$$
\Lambda[[M X] X\}^{+}=f\left(\lambda_{[M X]^{2+}}^{\circ}, \lambda_{[[M X] X\}^{+}}^{\circ}, \lambda_{X^{-}}^{\circ}, K_{A}^{(1)}, K_{A}^{(2)}, R\right)
$$

where $\mathrm{R}$ is the average center to center distance for the ion pairs. A multi parameter "least square" curve-fitting procedure is used to give the lowest value of curve fitting parameter $\sigma(\Lambda)$ between the experimental and calculated points. An alterative numerical method which was found to be very successful has been used to find the minimum $\sigma(\Lambda)$ (Jones and Bradshow, 1933). where :

$$
\sigma \Lambda=\left[\frac{\sum_{n=1}^{N P}\left(\Lambda_{\text {calc }}-\Lambda_{\text {exp }}\right)^{2}}{N P}\right]^{2}
$$

A computer program is used to analyze the concentration - conductivity measurements in which the input data are (T, D, $\eta$ ) where $T$ is the temperature in Kelvin, D and $\eta$ are the dielectric constant and viscosity (poise) of the solvent at that temperature.

Table $1(\mathrm{~A}, \mathrm{~B})$ show the molar concentrations and equivalent conductance of $[\mathrm{Zn}(1,10-$ phen $\left.)\left(\mathrm{H}_{2} \mathrm{O}\right)_{4}\right] \mathrm{Cl}_{2}$ in $60 \%$ and $80 \%$ methanol - water mixture at different temperatures. Fig. $1(A, B)$ show the relation between them. It can be seen from Table $1(A, B)$ that the equivalent conductance increase as temperature increase and decrease as methanol percent decrease suggesting an increasing tendency of the ions to associate into ion pairs since increasing both hydrogen bonding and viscosity of mixed solvent (Hameed et al., 2007). The decrease of equivalent conductance with increasing concentration were shown in fig.1(A,B) which obey Kolaraush equation of weak electrolytes .

$$
\Lambda=\Lambda_{\circ}-\mathbf{a} \sqrt{c}
$$

Where $\Lambda_{\circ}$ is the equivalent conductance at infinite dilution and a is Onsager slope.

Table (2) show the results of analysis of the complex $\left[\mathrm{Zn}\left(1,10\right.\right.$-phen) $\left.\left(\mathrm{H}_{2} \mathrm{O}\right)_{4}\right] \mathrm{Cl}_{2}$ in two percentages of methanol-water mixture $(60 \%$ and $80 \%)$ at different temperatures by using Lee-Wheaton equation for unsymmetrical electrolytes $(2: 1)$ which gives the values of $\left(\mathrm{K}_{\mathrm{A}}\right.$, $\lambda^{{ }^{0}}{ }^{2+}, \lambda_{\mathrm{MX}}{ }^{+}, \mathrm{R}$ and $\sigma \Lambda$ ).

The values of $\mathrm{K}_{\mathrm{A}}$ decrease with increasing temperature at each percentage because of breaking of $\mathrm{H}$-bonds formed at low temperature and this will lead to increasing of $\boldsymbol{\lambda}_{\mathbf{M}}{ }^{2+}$ as shown in table (2). Furthermore, $\mathrm{K}_{\mathrm{A}}$ is increase from $80 \%$ to $60 \%$ of methanol because of increasing $\mathrm{H}$ - bonding due to increasing water percentage and increasing viscosity which play an important role. Similar observation have also been noted for some electrolytes in the same mixed solvents (Hameed et al., 2008, Hameed et al., 2007) and in other mixed solvents (AL- Mustawi, 2002) and this may be attributed to the selective solvation of ions besides the solvodynamic viscose force ( Das and saha, 2000). The results of the distance paramenter $\mathrm{R}$ are large according to the following two effects: firstly isolated ions (in particular the cation) will tend to be surrounded by extensive solvent shells or the existence of these dielectrically saturated regions give rise to a repulsive force between the ions when 
they come into close approximately. The second effect is ion-dipole-ion-forces will be significant and solvent separated ion pair will have same stability (Lee and Wheaton ,1978; Naema, 2002)

$\lambda_{\mathrm{MX}^{+}}{ }^{+}$is almost constant with low values due to the formation of larger ion than $\lambda_{\mathrm{M}}{ }^{2+}$ and more stable than the other ions $\left(\mathrm{M}^{2+}, \mathrm{X}^{-}\right) \cdot \lambda^{\circ}{ }_{\mathrm{M}}{ }^{2+}$ at $80 \%$ methanol are higher than the other percent $60 \%$ according to the increasing dielectrically constant. The small values of $\sigma \Lambda$ give an indication of the good best fit value (less than 0.1).

Thermodynamic parameters from the association reaction are evaluated by the following equations:

$$
\begin{aligned}
& \mathrm{LnK}_{\mathrm{A}}=-\Delta \mathrm{H} / \mathrm{RT}+\mathrm{constant} \\
& \Delta \mathrm{G}=-\mathrm{RT} \ln K_{\mathrm{A}} \\
& \Delta \mathrm{S}=(\Delta \mathrm{H}-\Delta \mathrm{G}) / \mathrm{T}
\end{aligned}
$$

Where $\Delta \mathrm{H}$ is the enthalpy, $\Delta \mathrm{S}$ is entropy and $\Delta \mathrm{G}$ is free Gibb's energy.

The enthalpy evaluated from fig .(2) by plotting $\operatorname{lnKa}$ against $1 / \mathrm{T}$ from the equation (12).

Results of the calculation are shown in Table (3). It is well known that addition of an electrolyte to a solvent causes some structural changes due to the rupture of the bonds between solvent molecules from one side and to the interaction of ions with each other and with solvent molecules from the other side (Atkins, 1986).

$\Delta \mathrm{H}$ of ion association reaction according to the activated complex theory is a result of the energies being expanded for the destruction of solvent - solvent bonds and the formation of solvent ion bonds. As can be noticed from Table (3), $\Delta \mathrm{H}$ decrease with decreasing methanol percentage due to the broken of ion -ion bond in solution as a result of increasing dielectric constant of the solvent by increasing water percentage (Tominic et al., 2004). The entropy is positive as water percentage increase in the solvent mixture and this may be recognized as a structure - maker in these media. Finally, the values of $\Delta \mathrm{G}$ are negative which indicate that the reaction is spontaneous. 
Table 1-A: The equivalent conductivities $\Lambda\left(\Omega^{-1} \cdot \mathrm{cm}^{2}\right.$.equiv $\left.{ }^{-1}\right)$ with molar concentrations $\mathrm{C}$ (mole/L)for $\left[\mathrm{Zn}(1,10\right.$-Phen $\left.)\left(\mathrm{H}_{2} \mathrm{O}\right)_{4}\right] \mathrm{Cl}_{2}$ in $80 \%$ methanol water mixtures at different temperatures.

\begin{tabular}{|c|c|c|c|c|c|c|c|c|c|}
\hline \multicolumn{2}{|c|}{$\mathbf{2 8 8 . 1 5}$ K } & \multicolumn{2}{c|}{$\mathbf{2 9 3 . 1 5}$ K } & \multicolumn{2}{c|}{$\mathbf{2 9 8 . 1 5}$ K } & \multicolumn{2}{c|}{$\mathbf{3 0 3 . 1 5}$ K } & \multicolumn{2}{c|}{$308.15 ~ K$} \\
\hline $\mathbf{C} \times \mathbf{1 0}^{\mathbf{4}}$ & $\Lambda$ & $\mathbf{C} \times \mathbf{1 0}^{\mathbf{4}}$ & $\Lambda$ & $\mathbf{C} \times \mathbf{1 0}^{\mathbf{4}}$ & $\Lambda$ & $\mathbf{C} \times \mathbf{1 0}^{\mathbf{4}}$ & $\Lambda$ & $\mathbf{C} \times \mathbf{1 0}^{\mathbf{4}}$ & $\Lambda$ \\
\hline 0.74 & 180.387 & 0.19 & 187.272 & 0.74 & 198.288 & 0.74 & 217.566 & 0.74 & 225.828 \\
\hline 0.90 & 179.520 & 1.07 & 186.592 & 0.90 & 195.228 & 0.90 & 210.936 & 0.90 & 222.156 \\
\hline 1.07 & 178.024 & 1.23 & 186.879 & 1.07 & 195.160 & 1.07 & 206.584 & 1.07 & 218.960 \\
\hline 1.23 & 176.081 & 1.38 & 187.094 & 1.23 & 194.354 & 1.23 & 202.659 & 1.23 & 216.779 \\
\hline 1.53 & 175.191 & 1.53 & 185.889 & 1.38 & 193.749 & 1.53 & 197.257 & 1.53 & 212.636 \\
\hline 1.67 & 175.032 & 1.67 & 184.824 & 1.53 & 192.576 & 1.67 & 195.228 & 1.67 & 210.528 \\
\hline 1.80 & 174.782 & 1.80 & 184.397 & 1.67 & 190.944 & 1.80 & 194.013 & 1.80 & 209.285 \\
\hline 1.94 & 173.910 & 1.94 & 183.923 & 1.80 & 190.774 & 1.94 & 191.828 & 1.94 & 208.692 \\
\hline 2.06 & 173.502 & 2.06 & 183.388 & 2.06 & 189.814 & 2.06 & 191.297 & 2.06 & 208.104 \\
\hline 2.19 & 172.059 & 2.19 & 183.250 & 2.19 & 189.778 & 2.19 & 190.711 & 2.19 & 206.565 \\
\hline 2.31 & 171.496 & 2.31 & 182.546 & 2.31 & 189.618 & 2.31 & 190.502 & 2.31 & 205.972 \\
\hline
\end{tabular}

Table 1-B : The equivalent conductivities $\Lambda\left(\Omega^{-1} \cdot \mathrm{cm}^{2}\right.$.equiv $\left.{ }^{-1}\right)$ with molar concentrations $\mathrm{C}$ (mole/L) for $\left[\mathrm{Zn}(1,10-\mathrm{Phen})\left(\mathrm{H}_{2} \mathrm{O}\right)_{4}\right] \mathrm{Cl}_{2}$ in $60 \%$ methanol water mixtures at different temperatures.

\begin{tabular}{|c|c|c|c|c|c|c|c|c|c|}
\hline \multicolumn{2}{|c|}{$\mathbf{2 8 8 . 1 5} \mathbf{K}$} & \multicolumn{2}{c|}{$\mathbf{2 9 3 . 1 5} \mathbf{K}$} & \multicolumn{2}{c|}{$\mathbf{2 9 8 . 1 5} \mathbf{K}$} & \multicolumn{2}{c|}{$\mathbf{3 0 3 . 1 5 ~ K}$} & \multicolumn{2}{c|}{$\mathbf{3 0 8 . 1 5 ~ K}$} \\
\hline $\mathbf{C} \times \mathbf{1 0}^{4}$ & $\Lambda$ & $\mathbf{C} \times \mathbf{1 0}^{4}$ & $\Lambda$ & $\mathbf{C} \times \mathbf{1 0}^{4}$ & $\Lambda$ & $\mathbf{C} \times \mathbf{1 0}^{4}$ & $\Lambda$ & $\mathbf{C} \times \mathbf{1 0}^{4}$ & $\Lambda$ \\
\hline 0.19 & 161.262 & 0.19 & 166.464 & 0.19 & 156.060 & 0.19 & 150.858 & 0.19 & 156.060 \\
\hline 0.38 & 153.816 & 0.38 & 156.468 & 0.38 & 153.816 & 0.38 & 151.164 & 0.56 & 153.170 \\
\hline 0.56 & 145.962 & 0.56 & 153.170 & 0.56 & 151.368 & 0.56 & 149.566 & 0.90 & 152.592 \\
\hline 0.74 & 143.208 & 0.74 & 150.093 & 0.74 & 148.716 & 0.90 & 149.226 & 1.23 & 151.994 \\
\hline 0.90 & 142.494 & 0.90 & 148.104 & 0.90 & 148.104 & 1.07 & 148.512 & 1.38 & 151.597 \\
\hline 1.23 & 133.722 & 0.10 & 146.608 & 1.07 & 147.560 & 1.23 & 147.900 & 1.53 & 151.787 \\
\hline 1.38 & 133.849 & 1.38 & 146.421 & 1.23 & 146.180 & 1.53 & 147.775 & 1.67 & 150.552 \\
\hline 1.53 & 131.727 & 1.53 & 145.100 & 1.53 & 145.769 & 1.80 & 147.631 & 1.80 & 149.893 \\
\hline 1.67 & 121.788 & 1.67 & 144.432 & 1.67 & 145.044 & 1.94 & 147.560 & 2.19 & 149.211 \\
\hline 1.80 & 121.046 & 1.80 & 143.671 & 1.80 & 144.802 & 2.06 & 146.809 & 2.31 & 148.070 \\
\hline 1.94 & 120.683 & 1.94 & 143.344 & 1.94 & 144.398 & 2.19 & 146.413 & 2.42 & 149.787 \\
\hline
\end{tabular}




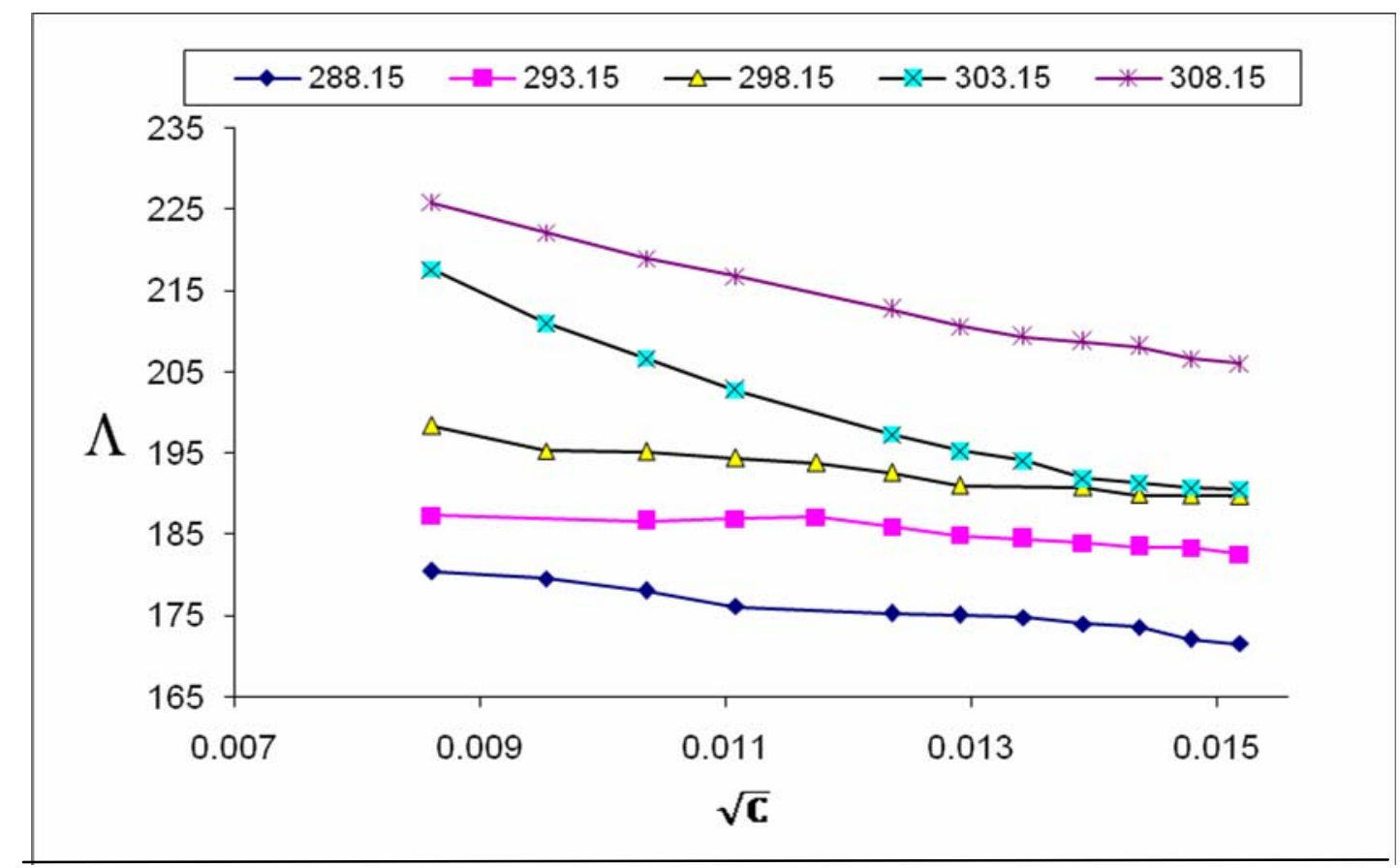

Fig. 1-A: Plot of equivalent conductivities $\Lambda\left(\Omega^{-1} \cdot \mathrm{cm}^{2}\right.$.equiv $\left.{ }^{-1}\right)$ against square root of concentration (mole/L) for $\left[\mathrm{Zn}(\right.$ phen $\left.)\left(\mathrm{H}_{2} \mathrm{O}\right)_{4}\right] \mathrm{Cl}_{2}$ in $80 \%$ methanol-water mixtures at different temperatures.

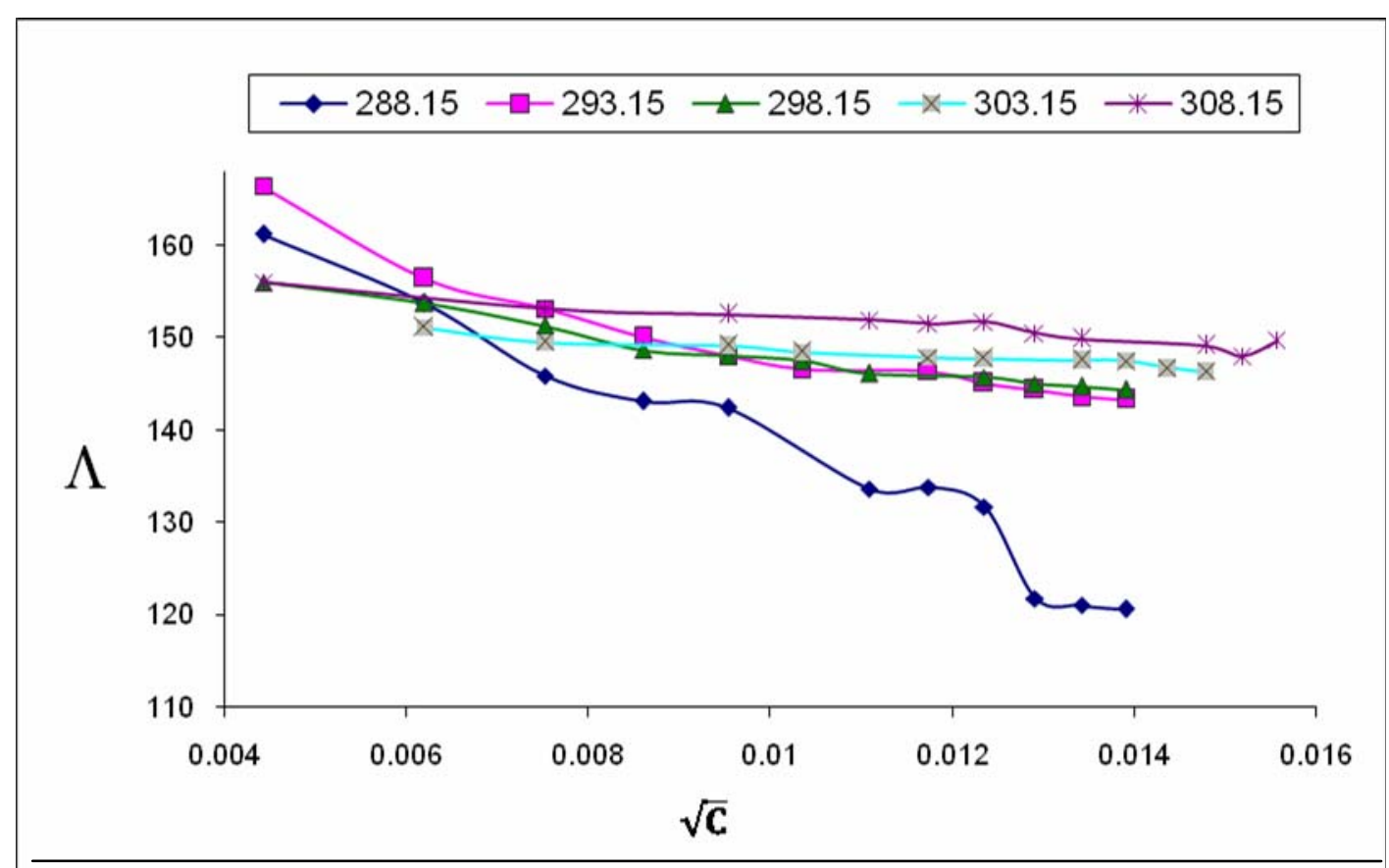

Fig. 1-B: Plot of equivalent conductivities $\Lambda\left(\Omega^{-1} \cdot \mathrm{cm}^{2}\right.$.equiv $\left.{ }^{-1}\right)$ against square root of concentration $(\mathrm{mole} / \mathrm{L})$ for $\left[\mathrm{Zn}(\right.$ phen $\left.)\left(\mathrm{H}_{2} \mathrm{O}\right)_{4}\right] \mathrm{Cl}_{2}$ in $60 \%$ methanol -water mixtures at different temperatures. 
Table 2: The results of analysis of the conductance data for $\left[\mathrm{Zn}(\mathrm{Phen})\left(\mathrm{H}_{2} \mathrm{O}\right)_{4}\right] \mathrm{Cl}_{2}$ in methanol-water mixtures at different temperature by using Lee-Wheaton equation.

\begin{tabular}{|c|c|c|c|c|c|}
\hline \multicolumn{7}{|c|}{$\mathbf{6 0 \%}$ methanol-water } \\
\hline Temp. $\mathbf{K}$ & $\mathbf{K}_{\mathbf{A}}$ & $\lambda_{\mathrm{M}^{2+}}^{\mathrm{o}}$ & $\lambda_{\mathrm{MX}^{+}}^{\mathrm{o}}$ & $\left.\mathbf{R} \mathbf{( A}^{\circ}\right)$ & $\sigma \Lambda$ \\
\hline 288.15 & 783 & 105 & 0.01 & 58 & 0.047 \\
\hline 293.15 & 772 & 120 & 0.01 & 54 & 0.031 \\
\hline 298.15 & 750 & 122 & 0.01 & 52 & 0.055 \\
\hline 303.15 & 720 & 124 & 0.01 & 51 & 0.061 \\
\hline 308.15 & 680 & 126 & 0.01 & 50 & 0.063 \\
\hline \multicolumn{7}{|}{$\mathbf{8 0 \%}$ methanol-water } \\
\hline 288.15 & 191 & 136 & 0.01 & 50 & 0.047 \\
\hline 293.15 & 185 & 148 & 0.01 & 49 & 0.040 \\
\hline 298.15 & 160 & 154 & 0.01 & 47 & 0.051 \\
\hline 303.15 & 146 & 156 & 0.01 & 43 & 0.009 \\
\hline 308.15 & 141 & 174 & 0.01 & 40 & 0.008 \\
\hline
\end{tabular}

Table 3: Thermodynamic parameters $(\Delta \mathrm{H}, \Delta \mathrm{G}, \Delta \mathrm{S})$ of the complex in two solvent composition.

\begin{tabular}{|c|c|c|c|}
\hline Temp. K & $-\Delta \mathbf{G}$ cal.mol ${ }^{-1}$ & $\Delta S$ cal.mol ${ }^{-1} \mathbf{k}^{-1}$ & $-\Delta \mathrm{H}$ cal.mol ${ }^{-1}$ \\
\hline \multicolumn{4}{|c|}{$60 \%$ methanol-water } \\
\hline 288.15 & 3801.56 & 8.92104 & \multirow{5}{*}{1230.97} \\
\hline 293.15 & 3859.32 & 8.96589 & \\
\hline 298.15 & 3908.07 & 8.97906 & \\
\hline 303.15 & 3949.11 & 8.96633 & \\
\hline 308.15 & 3979.37 & 8.91905 & \\
\hline \multicolumn{4}{|c|}{$80 \%$ methanol-water } \\
\hline 288.15 & 2996.62 & 0.09649 & \multirow{5}{*}{2968.81} \\
\hline 293.15 & 3030.09 & 0.20902 & \\
\hline 298.15 & 2996.06 & 0.0914 & \\
\hline 303.15 & 2991.35 & 0.07433 & \\
\hline 288.15 & 2996.62 & 0.09649 & \\
\hline
\end{tabular}




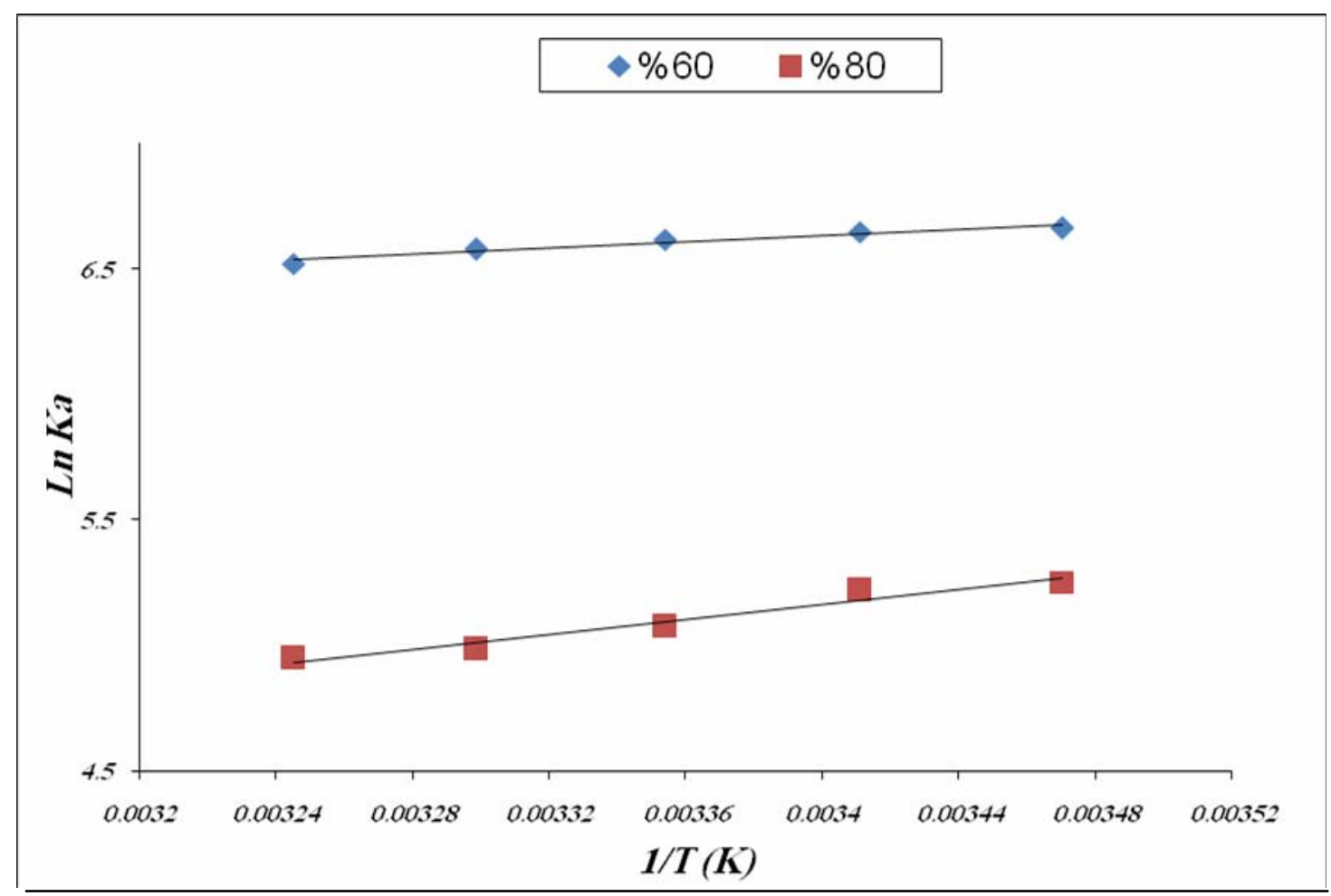

Fig. 2: Plot of $\operatorname{lnKa}$ against 1/T of the complexes at two solvent composition.

\section{REFERENCES}

AL - Allaf, Y. O. ; Shareef, O. A.; Hani , A. M. (2006). Conductometric study of association phenomena of tetra aqua -1,10- phenanthroline Magnisum(II) chloride in methanol-water mixture at different temperature. Tikrit. J. Pure Science., 11, 233-237.

Akrawi, B. A. ; AL-Allaf ,Y.O. (2002). Conductivity measurements of some transition metal (II) complexes in different solvents. Raf. J. Sci. , 13,76-84.

AL Mustawi, Y.O. (2002). Conductivity measurements of some transition metal complexes in different solvents and at different temperatures. Ph. D. Thesis, Mosul University, Iraq, $15 \mathrm{p}$.

Armarego, W. L. ; Perrin, D. D. (1998). "Purification of Laboratory Chemicals" , 4th edn., John Wiley and Sons, Inc., New York, pp. 50-51.

Atkins , P.W. (1986). "Physical Chemistry" . 3rd edn., Oxford University press.

Chang , C.H. ; Yarbor , J.W. ; Mann , D. E. ; Gautieri , R. F. (1978). Effects of 1,10phenanathroline and a Zinc complex of 1,10 -phenathroline on nucleic acid synthesis . J. PET. , 205 (1), 27 -32 .

Das , B. ; Saha , N. (2000). Electrical conductances of some symmetrical tetra alkyl ammonium salts in methanol, acetonitrile , and methanol (1) + acetonitrile (2) mixtures at 298.15 K. J. Chem . Eng . Data , 45 (1) , 2-5 .

Fukuda , Y.; Sone , K. (1972) . Studies of mixed chelates .I. Mixed copper (II) chelates with $\mathrm{N}, \mathrm{N}, \tilde{\mathrm{N}}, \tilde{\mathrm{N}}$ tetramethylethylenediamine and bidentate ligand. Bull. Chem. Soc. Jpn., $45,465-469$. 
Hameed , Y. O.; Thanon , F. A. ; Abdul- Rahman , S. H. (2008) . Electrical behavior of association phenomena of tetra aqua -1,10 - phenanthroline iron (II) chloride In methanol - water mixtures at different temperatures . J. Edu . Sci ., 21 (3) , 1-13.

Hameed , Y.O. ; Thanon , F. A.; Hani , A . M .(2007) . Conductivity study of tetra aqua 1,10 -phenanthroline cobalt (II) chloride $\left[\mathrm{Co}\left(1,10\right.\right.$-phen) $\left.\left(\mathrm{H}_{2} \mathrm{O}\right)_{4}\right] \mathrm{Cl}_{2}$ in methanol water mixture at different temperatures . N.J.C , 25,111 -123 .

Jones, G. ; Bradshow, B. C. (1933). The measurement of conductance of standard potassium chloride solution in absolute units. J. Amer . Chem . Soc. , 55 ,1760 1780 .

Kiss, Z.O. (1994). The Zinc chelator 1,10 - phenanthroline enhances the stimulatory effects of protein kinase $\mathrm{C}$ activators and staurosporine, but not sphingosine. Biochem. $J$. 298, 93 -98 .

Lee, W. H. ; Wheaton ,R. J. (1978). Conductance of symmetrical, unsymmetrical and mixed electrolytes part 1 . J. Chem. Soc. F. Trans II., 74,743-766.

Lee , W. H. ; Wheaton , R. J. (1978). Conductance of symmetrical, unsymmetrical and mixed electrolytes part2 . J. Chem. Soc. F. Trans II .,74,1456-1482 .

Meter , M.V. ; Newmann , H. M. (1976). Solvation of the tris (1,10-phenanthroline) iron (II) cation as measured by solubility and nuclear magnetic resonance shifts. $J$. Amer. Chem. Soc. , 98 ,1382 -1388 .

Malik ,W.U. ; Benbi , R. ; Bhardwaj ,V.K. (1980). Metal chelates of some N-Acyl hydroxamic acids containing sulphonimido group. J. Indian. Chem. Soc., 1 (2), $35-$ 38.

Newmann, D. S. ; Blinn, E.; Carlson,L. (1979). The dissociation of $(5,7,7,12,14,14-$ Hexamethy1-1,4,8,11-tetra azacycotetradeca -4,11,diene (nickel (II) Sulfate dehydrate in water -dioxane solution . J. Phys .Chem. , 83 ,676-680.

Naema , H. A. (2002). Conductance investingation of ion-pair formation by sodium acetate in methanol water mixture . Iraqi , J. Chem. , 28(1), 97-105 .

Palyal , I. N. ; Lebed , A.V. ; Mchedloy , N. O. (2010). Association and transport properties in solvents of medium and low relative permittivity: quaternary ammonium picrates in acetone n-hexane mixed solvents. J. Molecular Liquid ., 10, 1016-1025.

Tamingo , T. (1975) . Solute -solvent interaction of metal chelate and onium electrolytes by study of viscosity and apparent molal volume in methanol, acetone and nitrobenzene . J. Phys. Chem., $79,1664-1670$.

Tominic, I. ; Tomas, R.; Vissic, M. ; Sokol, V. (2004). Conductometric study of hydrobromic acid in 2- Propanol +Water mixtures. Croat . Chem. Acta. , 77(3), 537-543. 